\title{
Weaning from mechanical ventilation: International Consensus Conference in Intensive Care Medicine
}

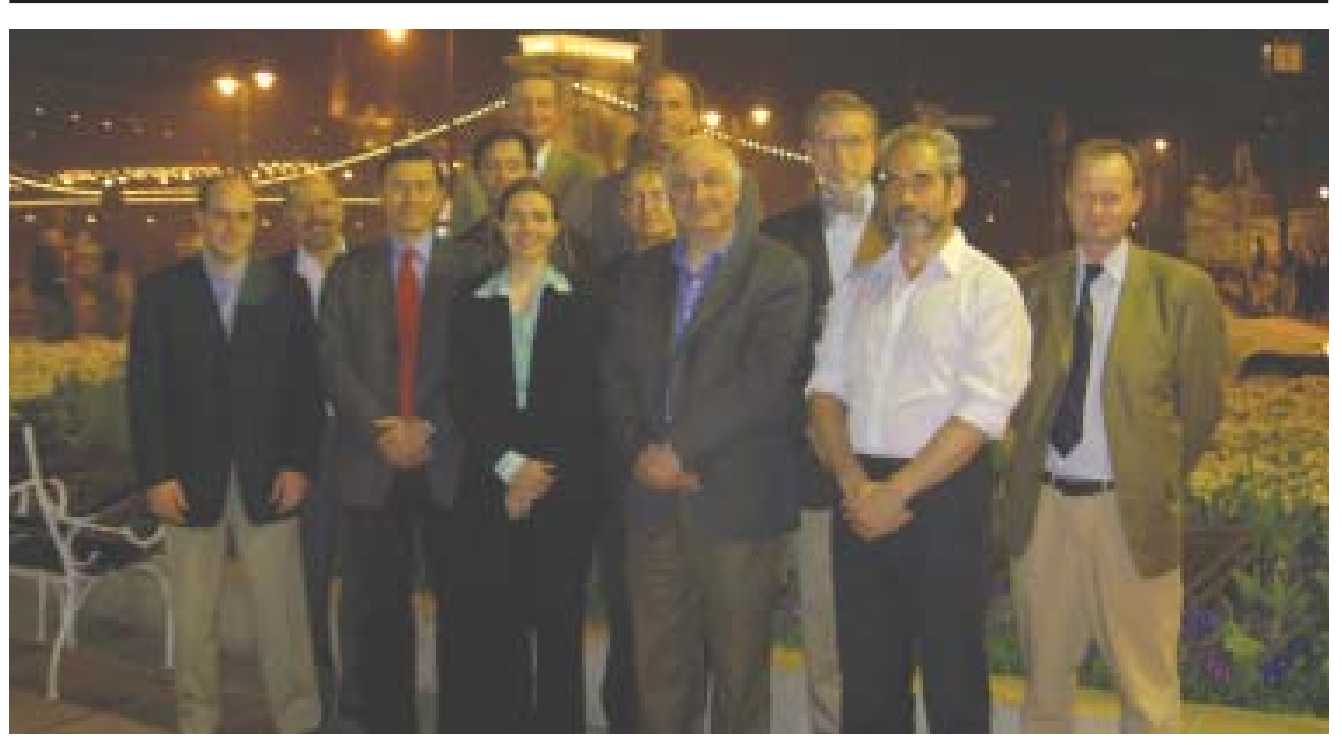

In April 2005, 155 participants from 27 countries attended the 5th International Consensus Conference in Intensive Care Medicine, held in Budapest (Hungary). The purpose of the Consensus Conference was to invite debate on each of five questions on the topic of "Weaning from mechanical ventilation", with the aim of evaluating the available scientific information and advancing understanding in the field.

The conference was jointly organised by the following five societies: American Thoracic Society (ATS), European Respiratory Society (ERS), European Society of Intensive Care Medicine (ESICM), Society of Critical Care Medicine (SCCM), and Société de Réanimation de Langue Française (SRLF). The ERS was in charge of the organisation of the conference itself.

The conference was held over 2 days, during which experts chaired five separate sessions, with a total of 27 talks presented by specialists in each area. Each session addressed a different aspect of weaning, from epidemiology and pathophysiology, to the management of patients with weaning failure. All the sessions were extremely well received by the participants, who gave positive feedback on the quality of the presentations and the organisation of the conference.

To fulfil the aims of the conference, a jury of 11 members of non-experts in the field attended each of the sessions, and then met over the subsequent 2 days to evaluate the available literature and prepare a consensus statement on each of the five questions discussed. The jury, chaired by Jean-Michel Boles, from Brest, France, included members from the USA, Canada and Europe. Their varied backgrounds and nationalities promoted lively debate to reach a consensus, with some jury members working almost through the night in order to write their contributions, only pausing briefly to sample the delights of
J-M. Boles ${ }^{1}$

C. Biles

${ }^{1}$ Service de Réanimation Médicale et Urgences Médicales Hôpital de la Cavale Blanche Brest

France

The 11 members of the Jury in front of Castle Hill, next to the Danube. 


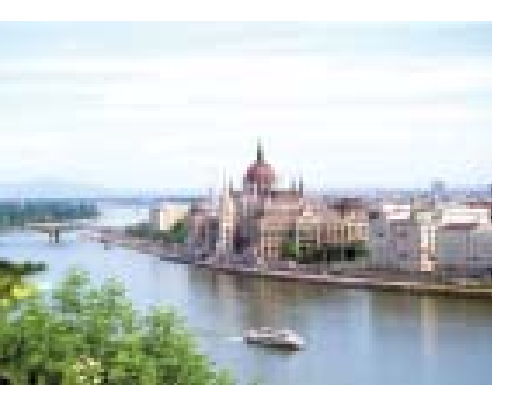

Hungarian fare. The Consensus statement will be published later this year after acceptance by the board of administrators of the five organising societies and final peer review.

The conference was held in the Buda district of Budapest, and the picturesque setting of the historic castle area and the panorama over the city and the River Danube was much appreciated by the participants. For one or two participants, this, along with the unseasonably warm weather, proved to be rather too much of a draw, as they were conspicuously absent from some of the sessions, although perhaps they were continuing research in some of the local coffee shops.

The presentations given at each session are available on the ERS website, at www.ersnet.org/elearning. 